\title{
MISSING TOOTH: A NEW TECHNIQUE TO MAINTAIN THE SPACE FOR PROSTHETIC REPLACEMENT DURING ORTHODONTIC TREATMENT - A REPORT OF TWO CASES
}

\begin{abstract}
Z. Radzi, N.A. Yahya, N. Zamzam, R.J. Spencer. Missing tooth: A new technique to maintain the space for prosthetic replacement during orthodontic treatment. Annal Dent Univ Malaya 2004; 11: 1-6.
\end{abstract}

\begin{abstract}
Missing teeth can be due to hypodontia, trauma or extraction. In general, the options for treatment depend on the severity of the hypodontia and the severity of the malocclusion. Occasionally, the space from missing teeth has to be maintained for prosthetic replacement and require an orthodontic/restorative approach. It is very important to ensure the space maintained is adequate for aesthetic reason so that it can be replaced with a prosthesis after the orthodontic treatment is completed. This article discusses a new innovation and clinical technique for maintaining this space during orthodontic treatment by using an acrylic tooth with several modifications. This innovation will be illustrated using two cases.
\end{abstract}

Key words: missing teeth, orthodontics.

\section{INTRODUCTION}

Missing teeth is one of the common problems seen in clinical dental practice. It can be due to hypodontia, trauma or extraction. The most commonly missing tooth is the lateral incisor with an incidence ranging from $0.52 \%$ to $8.4 \%$ (1). Several factors must be taken into account at the time of treatment planning. There is much to be gained from the interdisciplinary management of people who have missing teeth. True interdisciplinary management involves the close working of a committed team where the members contribute their expertise to achieve an optimum outcome (2). In general, the options for treatment depend on the age of the patient, severity of the missing teeth, degree of crowding and the severity of the malocclusion. Orthodontic treatment can greatly facilitate any restorative treatment or sometimes even eliminate the need for it (3). Occasionally, the space from missing teeth has to be maintained for prosthetic replacement and this requires an orthodontic/ restorative approach. There have been many advances in orthodontic and restorative procedures. These can be combined to provide a very powerful tool in providing the optimum result (4). The majority of orthodontic patients have crowded teeth

\section{Z. Radzi1 ${ }^{1}$ N.A. Yahya ${ }^{2}$, N. Zamzam¹, R.J. Spencer ${ }^{3}$ \\ ${ }^{1}$ Department of Children's Dentistry \& Orthodontics Faculty of Dentistry, University of Malaya 50603, Kuala Lumpur. \\ ${ }^{2}$ Department of Conservative Dentistry Faculty of Dentistry, University of Malaya 50603, Kuala Lumpur. \\ ${ }^{3}$ Consultant Orthodontist \\ Pinderfields General Hospital \\ Wakefield, West Yorkshire, United Kingdom. \\ Corresponding author - Zamri Radzi}

and require extractions to create the space for alignment of the remaining teeth. If teeth are missing or lost traumatically, then these can represent 'extractions'. A collaborative approach to clinical management can be organized in an either formal or informal way (5).

Among the treatment options are:

- Maintain the space

- Reopen the space

- Close the space

- Distribute the space

The treatment of missing teeth requires careful planning. The treatment objectives dependent on the approaches to be taken (6).

Several factors must be taken into account during treatment planning. In general the treatment options depend on the age of the patient, the severity of missing teeth, the amount of space available and the degree of crowding (3,7-9).

In order to provide a holistic treatment, each specialist must discuss and concur with the holistic treatment plan before embarking on any treatment procedure $(2,3)$. This will help each party to understand the other potential achievements and possible limitations. Orthodontics may contribute to the overall management of missing teeth by closing, opening or redistributing spaces (10). Other aspects of malocclusions such as crowding and arch discrepancies may be managed at the same time (6).

In cases of missing teeth, the presence of major malocclusion symptoms usually dictates the choice between space opening and space closure. In situations in which either treatment approach is feasible, the choice should be based on the evaluation 
of certain secondary criteria including the acceptability of the resulting functional occlusion (11-14).

From the restorative point of view, missing teeth can be replaced with either a bridge or an implant. An implant can commence only after the vertical growth has ceased so as the implant will not move with the adjacent teeth (15).

As regards to treatment alternatives for missing teeth, orthodontic space closure is to be preferred if good aesthetics are to be obtained. In some cases, however, such a result is difficult to obtain due to tooth anatomy, emergence profile, gingival height and asymmetry of midline. Space maintenance and redistribution of space to accept a prosthesis may be preferred if poor aesthetics is related to unsuitable colour, position or anatomy of adjacent teeth $(9,16-$ 18).

Factors to be considered include patient's malocclusion, opinion and cooperation. During the combined orthodontic/restorative clinic, both specialists should agree to the treatment plan and treatment sequences (5). Some restorative specialists prefer to construct the prosthesis only after the orthodontic treatment has completed. During the treatment, the orthodontist need to create the space and maintain it to the width of the contra lateral teeth (19-21).

Various methods currently used for space maintenance are as listed below (19-21):

(i) Using the bumper sleeves (Figure 1).

(ii) Using the step down bend (Figure 2).

(iii) Using coil or omega loops (Figure 3).

(iv) Using the closed coil spring (Figure 4).

(v) Using the acrylic tooth with the bracket bonded onto it (Figure 5).

The drawback with method (i) is that the bumper sleeves are made from an elastic material $(22,23)$. Therefore they are not rigid enough to maintain the space. The problem with methods (ii), (iii) and (iv) is that it is aesthetically unpleasant. The problem with method (v) is even though it is aesthetically pleasant; the acrylic tooth rotates around the brackets.

This article discusses the new innovation and clinical technique on how to solve the problems mentioned above by using an acrylic tooth with wings for space maintenance in two case reports.

\section{CASE REPORT 1}

\section{History}

A 15-year old male was referred to the orthodontic clinic by a private orthodontist for an integrated orthodontic and restorative approach. The patient complained of "upper front teeth are not straight and missing upper front tooth".

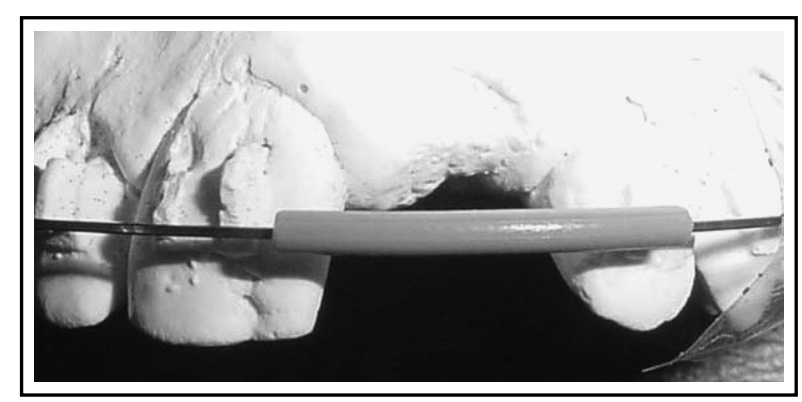

Figure 1: 'Bumper Sleeves'.

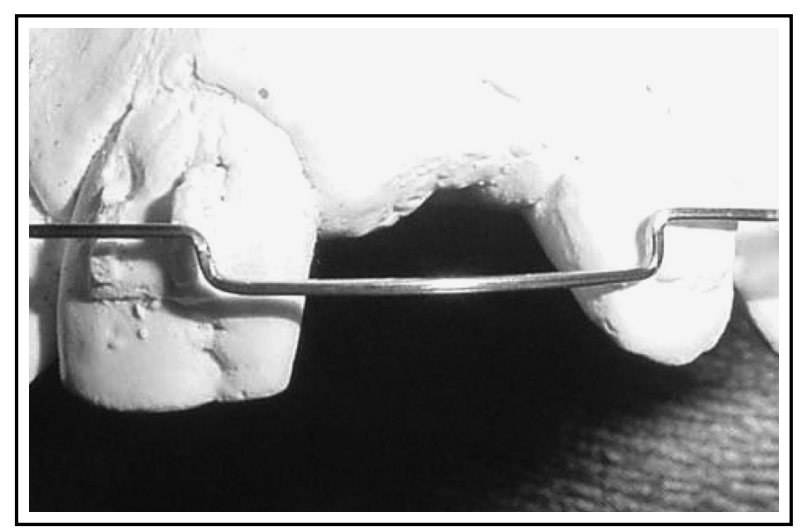

Figure 2: 'Step down bend'.

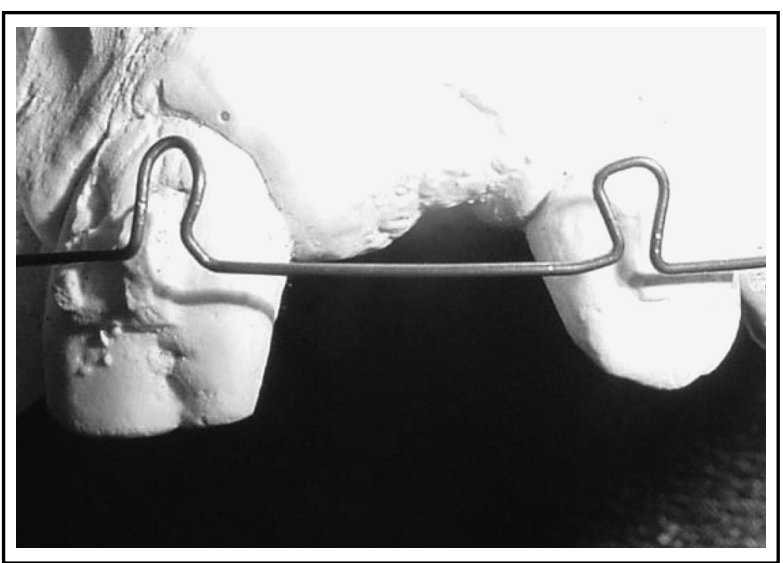

Figure 3: 'Omega Loops'.

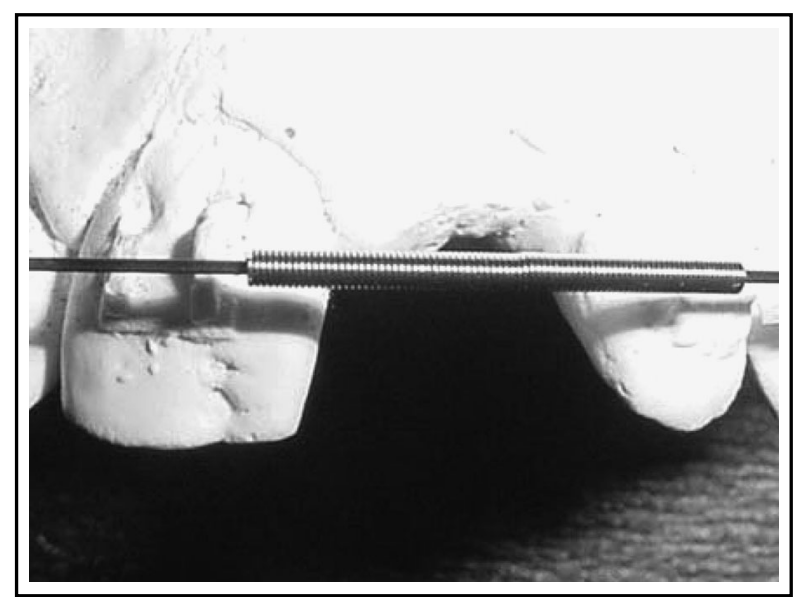

Figure 4: 'Closed coil spring'. 


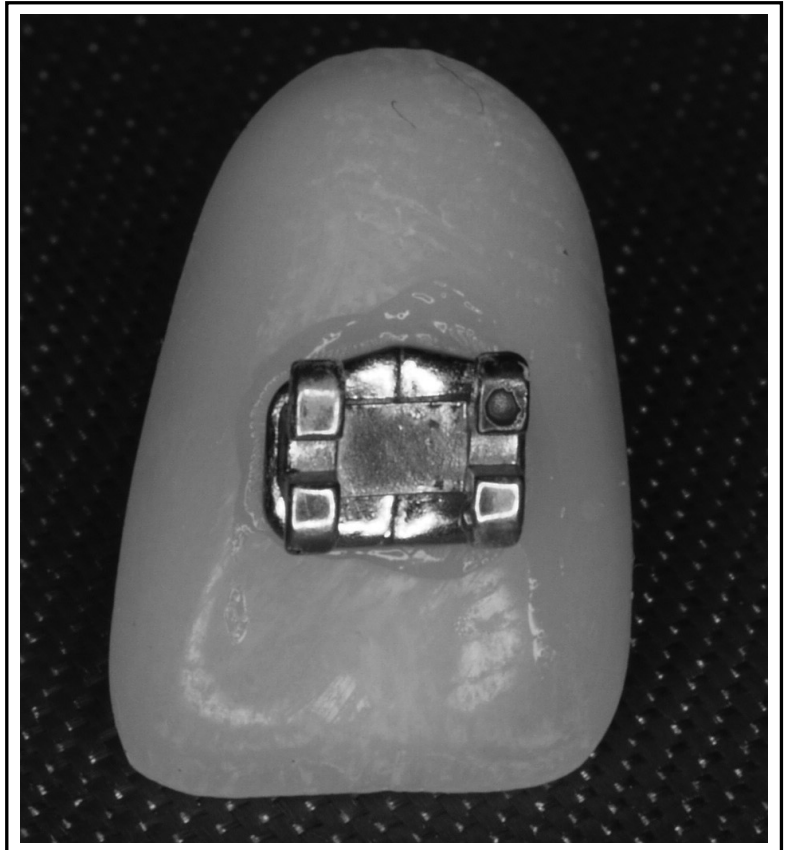

Figure 5: 'Acrylic tooth with bracket on'.

\section{Clinical findings}

The patient presented with a Class III incisor relationship on a Class I skeletal pattern. The main features include a missing upper left central incisor (21), reverse overjet, reduced overbite and crowding in both arches (Figures $6 \& 7$ ).

\section{Treatment}

The treatment planning involved the orthodontist and restorative specialists. The main treatment objectives included space opening for prosthesis replacement of missing 21, correction of overjet, overbite, crossbite and alignment of the teeth.

The treatment plan was formulated as follows:

Treatment initially involved the expansion of the maxilla. These were then followed by the extraction of all first premolars and upper and lower preadjusted Edgewise appliances. During the fixed appliances phase, the space was maintained using an acrylic tooth with wings (Figures $8 \& 9$ ). Once the orthodontic treatment is completed, the patient will wear a retainer with acrylic tooth. Subsequently, a

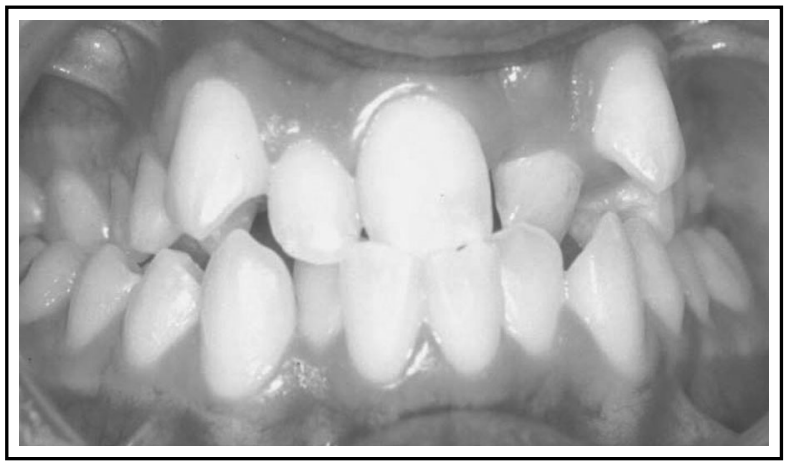

Figure 6: Pre-treatment anterior view.

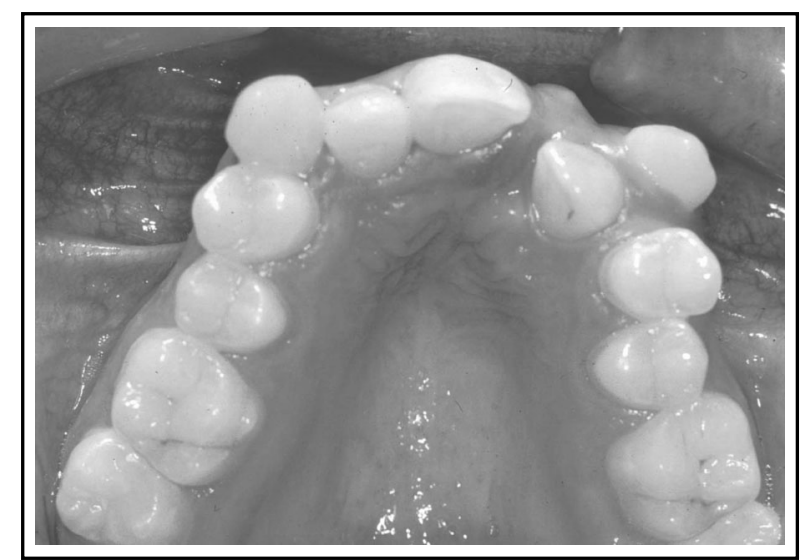

Figure 7: Pre-treatment upper occlusal view.

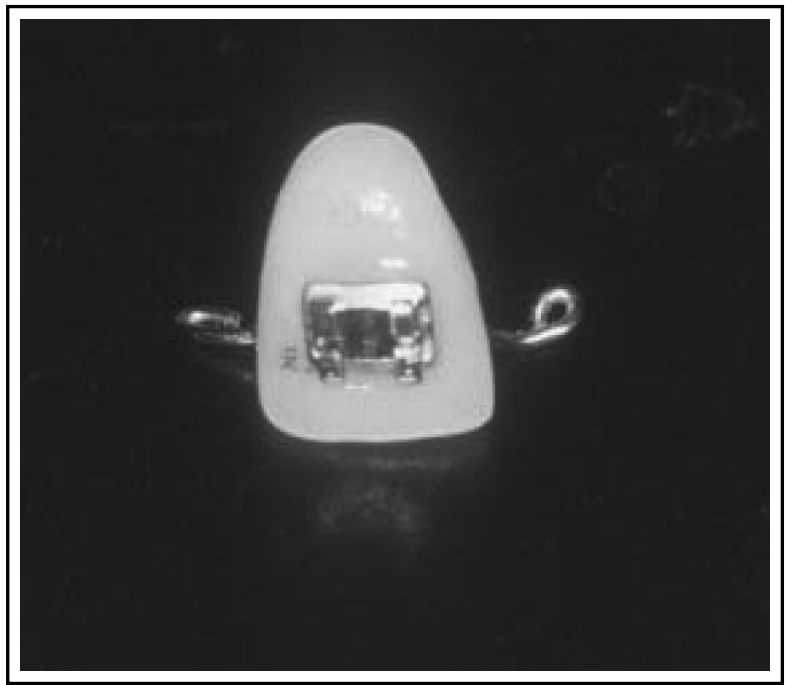

Figure 8: Acrylic tooth with modified wings (Labial view).

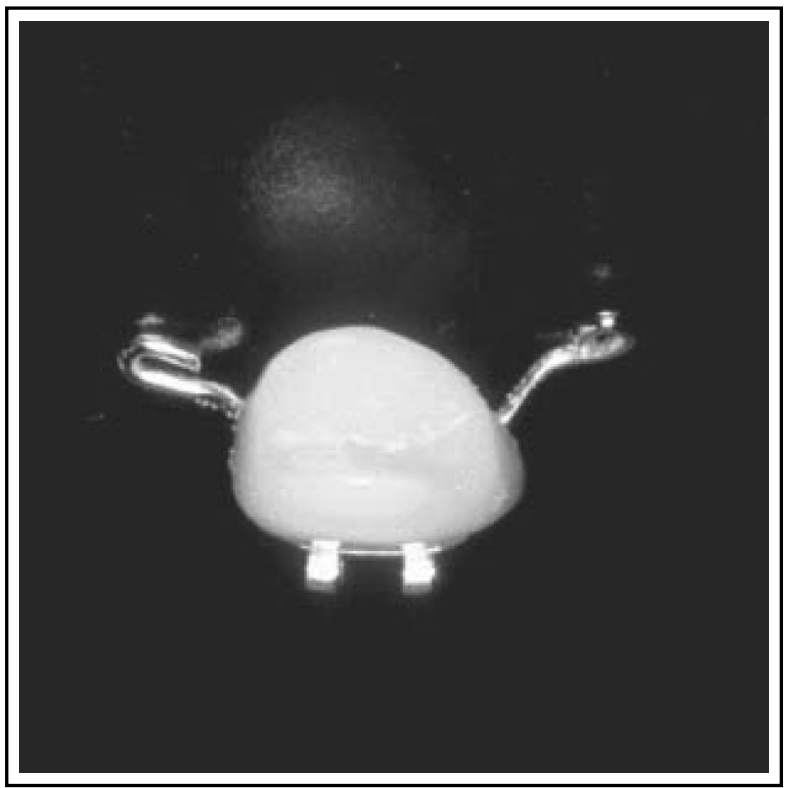

Figure 9: Acrylic tooth with modified wings (Occlusal view). 
resin bonded bridge will be constructed followed by an implant once the growth has ceased.

\section{Space maintenance}

The space was maintained with the newly designed false tooth with the wings. The laboratory and clinical procedures are summarized as follows:

1. Space was created to the same width of the contralateral tooth with fixed orthodontic appliances.

2. The upper and lower impressions were taken. The upper and lower working models were casted.

3. The colour of the adjacent tooth was recorded using Vita shade guide.

4. An acrylic tooth of the appropriate size, width and colour was selected.

5. The shape of the acrylic tooth was contoured according to the study models.

6. A groove was made horizontally on the palatal side about midway cervico-incisally.

7. A $0.7 \mathrm{~mm}$ stainless steel wire was bent into wings shape (Figure 10).

8. The acrylic tooth was positioned on the model.

9. The wings were placed into the groove.

10. The position of the wings was checked to ensure good adaptability with the adjacent teeth.

11. The groove was sealed with composite resin.

12. The occlusion was checked to avoid any occlusal interference.

13. An orthodontic bracket was bonded onto the labial surface of the acrylic tooth.

14. The acrylic tooth was tried on the patient and marked for the bracket position.

15. The labial surface was roughened with bur for retention roughly at the area that was marked for the bracket placement.

16. The bracket was tied to the arch wire with steel ligature (Figures $11 \& 12$ ).

\section{CASE REPORT 2}

\section{History}

A 47-year old male was referred to the orthodontic clinic by a general dental practitioner. Patient complained of 'uneven upper front teeth'.

\section{Clinical findings}

The patient presented with a class I incisor relationship on a class I skeletal base with missing upper right central incisor (11), lower right central incisor (41) and rotated upper right lateral incisor (22).

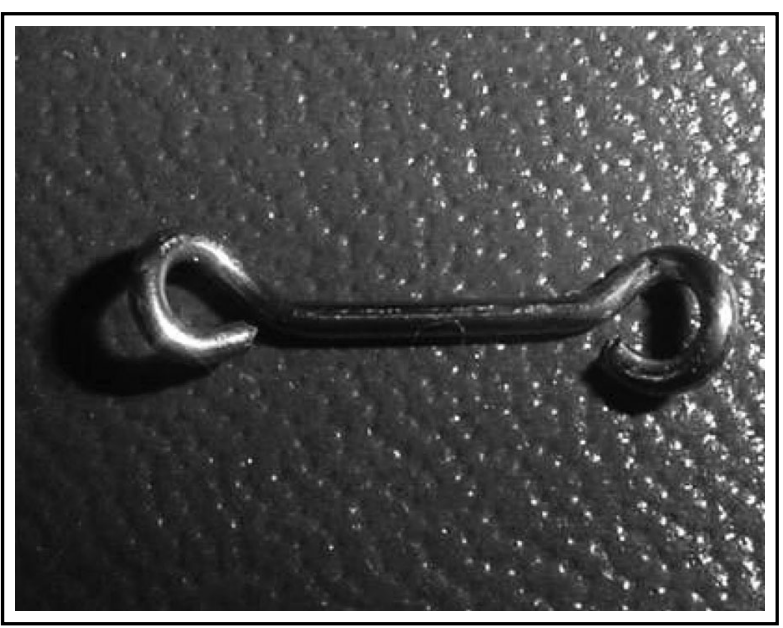

Figure 10: A $0.7 \mathrm{~mm} \mathrm{S.S} \mathrm{wire} \mathrm{was} \mathrm{bent} \mathrm{into} \mathrm{wings} \mathrm{shape.}$

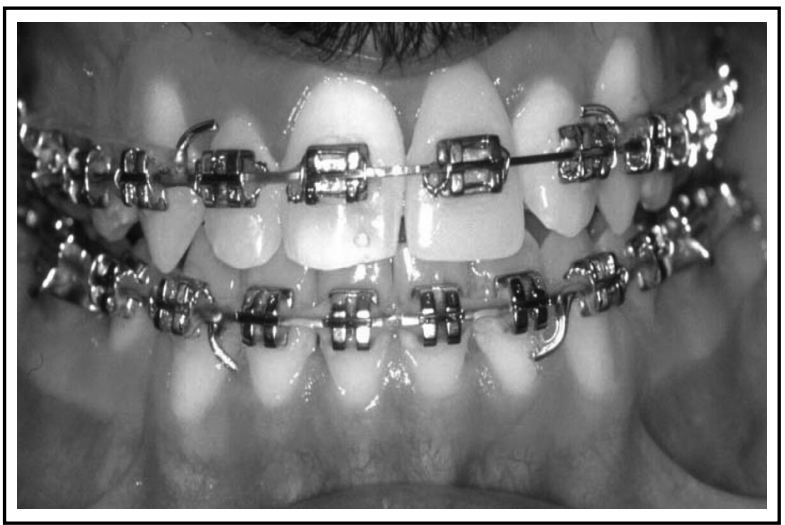

Figure 11: Anterior intra oral view. Acrylic tooth insitu.

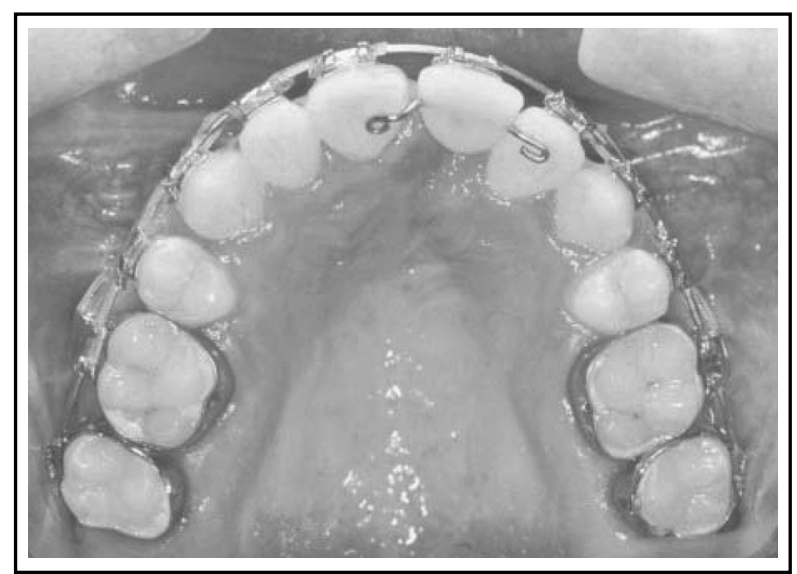

Figure 12: Occlusal view. Acrylic tooth insitu.

\section{Treatment}

Treatment aims and plan were formulated by a multidisciplinary team. The chief treatment objectives included an alignment and leveling, space creation for 11, space closure of 41 and maintaining good gingival conditions. 
Treatment plan included periodontal maintenance, upper and lower fixed appliances followed by implant replacement of the missing 11 .

\section{Treatment sequence}

The treatment initially involved periodontal treatment, followed by upper and lower preadjusted edgewise appliance. The space available for 11 was not enough when compared to the width of the contralateral tooth 21 . Thus, space was created using the active Niti coil spring (Figure 13). Space created was satisfactory and the acrylic tooth was placed using the same technique described in case report 1 (Figures 14-17). A few months later, the surgeon inserted the implant fixture. The false tooth was removed during surgery and reinserted immediately after the surgical procedures.

\section{CONCLUSIONS}

This article demonstrates the use of the acrylic tooth in maintaining the space during orthodontic treatment. The use of stainless steel wings has limited the rotation movement of the false tooth around the bracket and thus improves the patient's comfort. This technique will assist the clinician to improve the appearance of a patient with a missing tooth during orthodontic treatment.

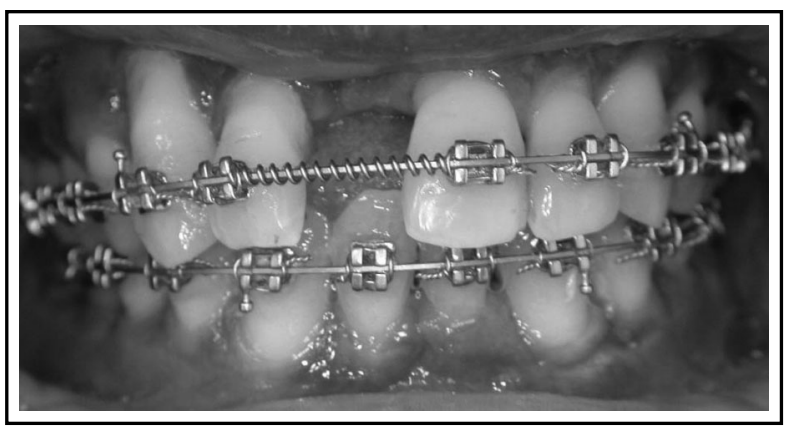

Figure 13: Anterior view.

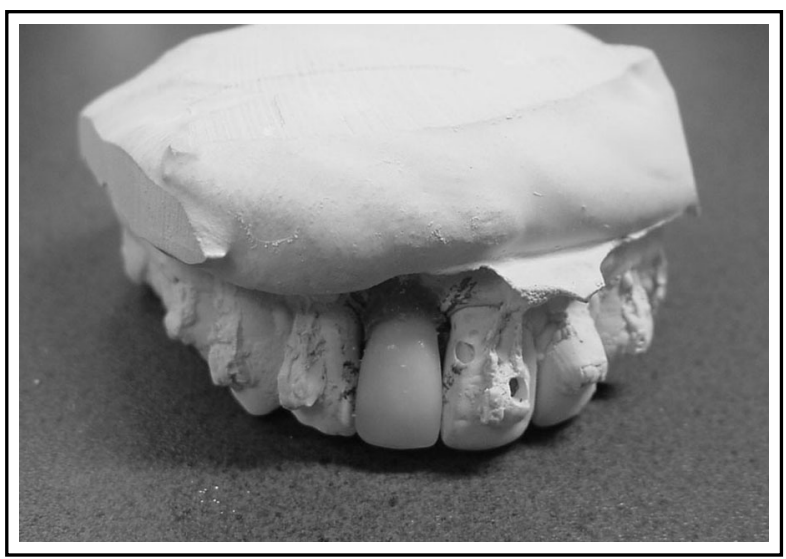

Figure 14: 'Try in' - Labial view.

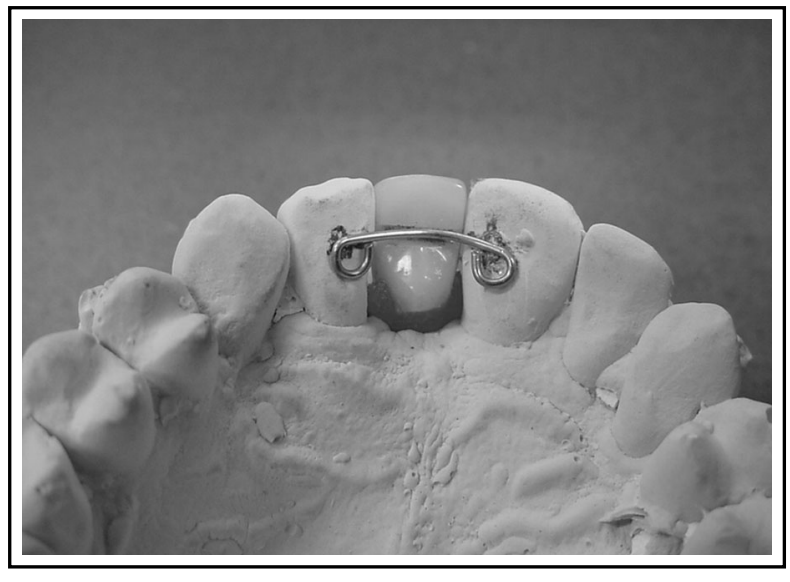

Figure 15: 'Try in' - Palatal view.

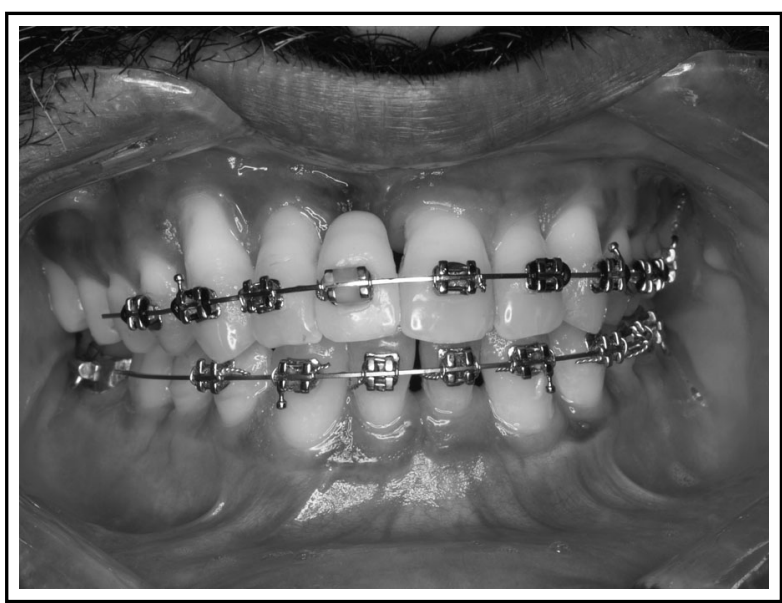

Figure 16: 'Acrylic tooth tied onto the archwire'Anterior view.

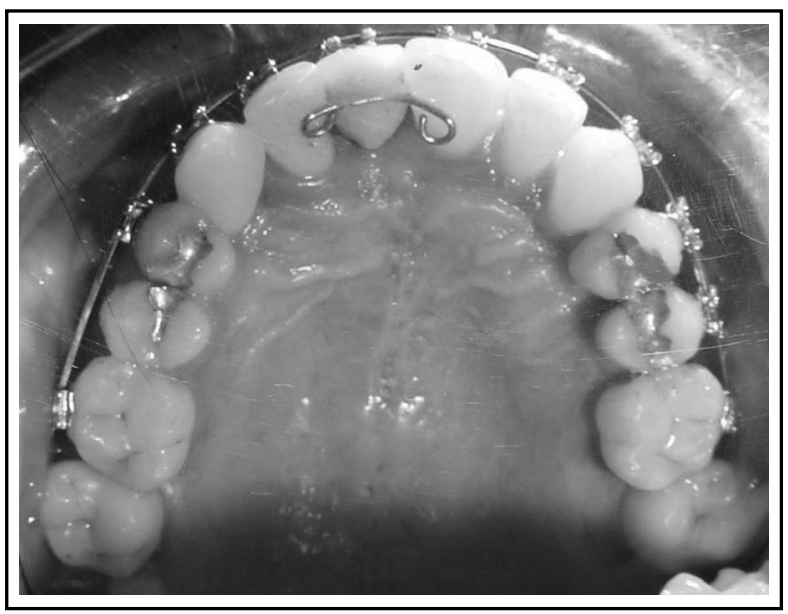

Figure 17: Occlusal view. 


\section{REFERENCES}

1. Brook AH. Dental anomalies of number, form and size. Their prevalence in British School Children. J Int Assoc Dent Child 1974; 5: $37-$ 53.

2. Nunn JH, Carter NE, Gillgrass TJ, Hobson RS, Jepson NJ, Meechan JG, Nohl FS. The Interdisclipnary management of hypodontia: background and role of paediatric dentistry. $\mathrm{Br}$ Dent J 2003; 194: 245-51.

3. Carter NE, Gilgrass, Hobson RS, Jepson N, Meechan JG, Nohl FS, Nunn JH. The interdislipnary management of hypodontia: orthodontics. Br Dent J 2003; 194: 361-6.

4. Alvesal L, Portin P. The inheritance pattern of missing, peg-shaped and strongly mesiodistally reduced upper lateral incisors. Acta Odontol Scand 1969; 27: 563-75.

5. Oliver RG. Edmund DH, Jagger RG, Jagger DC. A combine orthodontic/ Restorative Clinic. Rationale, Evolution and Experience. $\mathrm{Br} \mathrm{J}$ Orthod 1997; 24: 159-62.

6. Lewis DH, Eldridge DJ. Orthodontic/ Restorative Interface. Dent Update 1992; 18: 195-203.

7. Goodman JR, Jones SP, Hobkirk JA, King PA. Hypodontia: 1. Clinical and the management of mild to moderate hypodontia. Dent Update 1994; 21: 381-4.

8. Asher C, Lewis DH. The integration of orthodontic and restorative procedures in cases with missing maxillary incisors. Br Dent J 1986; 160: $241-5$.

9. Sabri R. Management of missing maxillary lateral incisors. J Am Dent Assoc 1999; 130: 804.

10. Millar BJ, Taylor NG. Lateral thinking: the management of missing upper lateral incisors. $\mathrm{Br}$ Dent J 1995; 178: 99-106.

11. Zacharison BU, Mjor IA. Remodelling of teeth by grinding. Am J Orthod 1975; 68: 545-53.

12. Zacharison BU. Improving orthodontic results in cases with maxillary incisors missing. Am J Orthod Dentofac Orthop. 1978; 73: 274-89.
13. Thordarson A, Zacharison BU, Mjor IA. Remodelling of canines to the shape of lateral incisors by grinding: A long term clinical radiographic evaluation. Am J Orthod Dentofac Orthop 1991; 100: 123-32 .

14. Tuverson DL. Orthodontic treatment using canines in place of missing lateral incisors. Am J Orthod Dentofac Orthop 1970; 58: 109-27.

15. Thilander B, Odman J, Grondahl K, Friberg B. Osseointegrated implants in adolescents. An alternative in replacing missing teeth. Eur $\mathbf{J}$ Orthod 1994; 16: 84-95.

16. Garn SM, Lewis AB. The gradient and the pattern of crown size reduction in simple hypodontia. Am J Orthod Dentofac Orthop 1970; 40: 51-8.

17. McNeill RW, Joondeph DR. Congenital absent maxillary lateral incisor: treatment planning considerations Angle Orthod 1973;43: 24-9.

18. Monofeldt I, Zacharisson B. Adjustment of clinical crown height by gingivectomy following orthodontic space closure. Am J Orthod Dentofac Orthop 1977; 47: 256-64.

19. Bennett JC, Mc Laughlin RP. Orthodontic Treatment Mechanics and the Preadjusted Appliance. 1st edn. Mosby-Wolfe. 1993: 9-78; 183-205.

20. Bennett JC, McLaughlin RP. Orthodontic management of the Dentition with the Preadjusted Appiance. ISIS Medical Media. 1997: 43-152.

21. McLaughlin RP. Bennett JC, Trevisi HJ. Systemized Orthodontic Treatment Mechanics. Mosby. 2001: 93-159.

22. Brantly WA, Eliades T. Orthodontic Materials. Scientific and Clinical Aspects. Thieme. 2001: 149; 173-88.

23. Langlade M. Optimization of Orthodontic Elastics. GAC International. 2000. 1-20. 